\title{
Effect of a provincial system of stroke care delivery on stroke care and outcomes
}

\author{
Moira K. Kapral MD MSc, Jiming Fang PhD, Frank L. Silver MD, Ruth Hall PhD, Melissa Stamplecoski BSc, \\ Christina O'Callaghan BAppSc, Jack V. Tu MD PhD
}

\begin{abstract}
Background: Systems of stroke care delivery have been promoted as a means of improving the quality of stroke care, but little is known about their effectiveness. We assessed the effect of the Ontario Stroke System, a province-wide strategy of regionalized stroke care delivery, on stroke care and outcomes in Ontario, Canada.
\end{abstract}

Methods: We used population-based provincial administrative databases to identify all emergency department visits and hospital admissions for acute stroke and transient ischemic attack from Jan. 1, 2001, to Dec. 31, 2010. Using piecewise regression analyses, we assessed the effect of the full implementation of the Ontario Stroke System in $\mathbf{2 0 0 5}$ on the proportion of patients who received care at stroke centres, and on rates of discharge to long-term care facilities and 30-day mortality after stroke.

Results: We included 243287 visits by patients with acute stroke or transient ischemic

$\mathrm{S}$ troke is a leading cause of death and disability worldwide..$^{1,2}$ Guidelines recommend that eligible patients receive care in a stroke unit, undergo neuroimaging and receive thrombolytic therapy, antithrombotic agents and screening for carotid stenosis. ${ }^{3-6}$ Many of these interventions require specialized resources, including clinicians with expertise in stroke care and rapid access to brain and vascular imaging; however, wide interfacility variations exist in the availability of such resources. . $^{7-10}$

To address regional disparities in resources and care, organizations such as the Canadian Stroke Network and the American Stroke Association have recommended the implementation of organized systems of stroke care delivery. ${ }^{11,12}$ Such systems are designed to facilitate access to optimal stroke care across an entire region and to promote the use of evidence-based therapies. ${ }^{11}$ However, little is known about the effect of stroke systems of care on outcomes in patients with stroke.

The province of Ontario was the first large jurisdiction in Canada, and in North America, to attack. The full implementation of the Ontario Stroke System in 2005 was associated with an increase in rates of care at stroke centres (before implementation: $40.0 \%$; after implementation: $46.5 \%$ ), decreased rates of discharge to long-term care facilities (before implementation: $16.9 \%$; after implementation: $14.8 \%$ ) and decreased 30-day mortality for hemorrhagic (before implementation: $38.3 \%$; after implementation: $34.4 \%$ ) and ischemic stroke (before implementation: $16.3 \%$; after implementation: $15.7 \%$ ). The system's implementation was also associated with marked increases in the proportion of patients who received neuroimaging, thrombolytic therapy, care in a stroke unit and antithrombotic therapy.

Interpretation: The implementation of an organized system of stroke care delivery was associated with improved processes of care and outcomes after stroke.

implement an integrated regional system of stroke care delivery. A system of coordinated stroke care, known as the Ontario Stroke System, was launched in 2000 and fully implemented in 2005 , resulting in a major transformation in the delivery of stroke care across the province. ${ }^{13} \mathrm{We}$ used population-based administrative and clinical data to evaluate the effect of the system's implementation on stroke care and outcomes.

\section{Methods}

\section{Setting}

We conducted a population-based retrospective analysis of patients discharged from hospital following either an emergency department visit or admission for acute stroke or transient ischemic attack between Jan. 1, 2001, and Dec. 31, 2010. Ontario is Canada's most populous province, with a population of more than 12.1 million at the midpoint of the study period. ${ }^{14}$ The province has more than 140 acute care institutions, with $40 \%$ of all hospitals located in rural areas. ${ }^{15}$
Competing interests: Frank Silver has received payments for board membership, lectures or travel expenses from Boehringer Ingelheim Canada, Bristol-Myers Squibb, Sanofi Canada and Bayer Canada. No other competing interests were declared.

This article has been peer reviewed.

Correspondence to: Moira K. Kapral, moira.kapral@uhn.on.ca

CMAJ 2013. DOI:10.1503 /cmaj.121418 
Residents have universal access to hospital care and physicians' services.

This study was approved by the Research Ethics Board of Sunnybrook Health Sciences Centre.

\section{Data sources and study sample}

We used 2 main data sources for this study. For analyses of rates of care at stroke centres, stroke case-fatality rates, and rates of admission to a long-term or chronic care facility after stroke, we used the Canadian Institute for Health Information's Discharge Abstract Database and National Ambulatory Care Reporting System database. These databases contain diagnostic and procedural information for all hospital admissions and emergency department visits in Ontario and have been extensively validated. ${ }^{16,17}$ We identified visits for stroke or transient ischemic attack using the International Statistical Classification of Dis-

Table 1: Components of the Ontario Stroke System

\begin{tabular}{|c|c|}
\hline Component & Description \\
\hline Ontario Stroke Network & $\begin{array}{l}\text { Provides central coordination and evaluation of } \\
\text { the Ontario Stroke System } \\
\text { (www.ontariostrokenetwork.ca) }\end{array}$ \\
\hline $\begin{array}{l}9 \text { regional stroke centres } \\
\text { and } 2 \text { enhanced district } \\
\text { stroke centres }\end{array}$ & $\begin{array}{l}\text { Responsible for organizing resources, patient } \\
\text { care and education across a region. Have } \\
\text { clinicians with expertise in stroke care as well as } \\
\text { neurosurgical and interventional radiology } \\
\text { facilities }\end{array}$ \\
\hline 16 district stroke centres & $\begin{array}{l}\text { Have clinicians with expertise in stroke care } \\
\text { as well as the capacity to provide thrombolytic } \\
\text { therapy and neuroimaging }\end{array}$ \\
\hline $\begin{array}{l}24 \text { secondary stroke } \\
\text { prevention clinics }\end{array}$ & Provide regional stroke prevention care \\
\hline $\begin{array}{l}\text { Regional transfer and } \\
\text { repatriation agreements }\end{array}$ & $\begin{array}{l}\text { Formalized agreements between organizations } \\
\text { to allow patients with stroke to be transferred } \\
\text { between institutions if needed }\end{array}$ \\
\hline $\begin{array}{l}\text { Emergency medical } \\
\text { services bypass protocols }\end{array}$ & $\begin{array}{l}\text { Agreements with emergency medical services } \\
\text { that allow ambulances to bypass the nearest } \\
\text { hospital to take patients with suspected stroke } \\
\text { to a regional stroke centre }\end{array}$ \\
\hline $\begin{array}{l}\text { Stroke best practices } \\
\text { recommendations }{ }^{20}\end{array}$ & $\begin{array}{l}\text { Evidence-based stroke care recommendations } \\
\text { and practice guidelines } \\
\text { (www.strokebestpractices.ca) }\end{array}$ \\
\hline Telestroke program ${ }^{22}$ & $\begin{array}{l}\text { Allows communication of patient clinical and } \\
\text { neuroimaging data to a stroke specialist; } \\
\text { facilitates use of thrombolytic therapy at } \\
\text { remote centres }\end{array}$ \\
\hline $\begin{array}{l}\text { Public awareness } \\
\text { campaigns }\end{array}$ & $\begin{array}{l}\text { Television advertising campaign about the } \\
\text { warning signs of stroke }\end{array}$ \\
\hline $\begin{array}{l}\text { Regional stroke education } \\
\text { programs }\end{array}$ & $\begin{array}{l}\text { Stroke education programs for providers, } \\
\text { patients and caregivers }\end{array}$ \\
\hline $\begin{array}{l}\text { Province-wide audit and } \\
\text { feedback of stroke care } \\
\text { delivery }^{15,23}\end{array}$ & $\begin{array}{l}\text { Ongoing data collection on processes of stroke } \\
\text { care through the Ontario Stroke Registry } \\
\text { (formerly the Registry of the Canadian Stroke } \\
\text { Network), with annual region-specific report } \\
\text { cards (www.rcsn.org) }\end{array}$ \\
\hline
\end{tabular}

eases and Related Health Problems, 10th revision (ICD-10), codes I60, I61, I63, I64, H34.1 and G45; these codes are endorsed by the Canadian Stroke Strategy and have been validated in Canadian populations. ${ }^{18-20} \mathrm{We}$ included patients aged 18-102 years and excluded those with an invalid health card number. Carotid endarterectomy and stenting were identified using procedure codes 1JE57 and 1JE50. Comorbid conditions were summarized using the Charlson-Deyo comorbidity index scale ${ }^{21}$ and were only available for patients admitted to hospital. Date of death was identified using the Registered Persons Database.

Because the administrative databases do not contain variables such as thrombolytic therapy and care in a stroke unit, we used the Ontario Stroke Audit database maintained by the Ontario Stroke Registry (formerly the Registry of the Canadian Stroke Network) to create a second cohort of patients with stroke, which we used for analyses of processes of care. Since 2002, the registry has conducted periodic audits on a random sample of all patients with stroke or transient ischemic attack seen at all institutions across Ontario, with patients identified using the ICD-10 codes listed above, and with detailed information collected on acute stroke management and outcomes. ${ }^{15}$ Validation by duplicate chart abstraction has shown excellent agreement for key variables including age, type of stroke, thrombolytic therapy and care in a stroke unit. ${ }^{15}$ Under provincial privacy legislation, the Ontario Stroke Registry is able to perform chart abstraction without individual patient consent. For the present study, we included all patients identified in 3 registry audits performed between Apr. 1, 2002, and Mar. 31, 2009.

\section{Intervention}

The intervention of interest was the provincewide implementation of the Ontario Stroke System (Table 1; ${ }^{15,20,22,23}$ Appendix 1, available at www.cmaj.ca/lookup/suppl/doi:10.1503/cmaj.12 1418/-/DC1). This system was initiated and funded by the Ontario Ministry of Health and Long-Term Care in 2000, with a phased implementation that was finalized in 2005 (www .ontariostrokenetwork.ca). Under the Ontario Stroke System, the province is divided into 11 regions, each of which has a regional stroke centre (a large institution with advanced resources for delivery of stroke care comparable to the comprehensive stroke centres established in the United States ${ }^{24}$ ) and a program director responsible for coordinating delivery of stroke care within the region. Each region may also have a number of district (or primary) stroke centres 
capable of providing more basic treatment to patients with stroke. Regional transfer agreements and ambulance bypass protocols permit patients with suspected stroke to be preferentially transported to designated stroke centres. Other components of the Ontario Stroke System include secondary stroke prevention clinics, provider education and institutional audit and feedback (Table 1). Administration of thrombolytic therapy at smaller hospitals is facilitated through the Ontario Telestroke Program. ${ }^{22}$

Although the Ontario Stroke System was launched in 2000, we selected 2005 as the cutpoint for evaluating its effect because this corresponded to the year the system was fully implemented, with finalization of regional networks, transfer agreements, infrastructure funding and transfer of responsibility for the program from the Ministry of Health and Long-Term Care to the regions.

\section{Outcomes}

The primary outcome was the proportion of patients with stroke or transient ischemic attack who received care at a regional or district stroke centre. Secondary outcomes were length of stay for patients admitted to hospital; discharge to a long-term care or chronic care facility after hospital admission for stroke; all-cause mortality at 30 days after stroke, stratified by type of stroke (ischemic or hemorrhagic); waiting times for carotid revascularization; thrombolytic therapy in patients with ischemic stroke and arrival to hospital within 2.5 hours after symptom onset; neuroimaging (computed tomography [CT] or magnetic resonance imaging [MRI] of the brain); carotid imaging (carotid Doppler ultrasonography, CT angiography, MR angiography or catheter angiography) in patients with ischemic stroke or transient ischemic attack; care in a stroke unit; dysphagia screening; and prescription of antithrombotic therapy among patients with ischemic stroke or transient ischemic attack.

\section{Statistical analysis}

We used data from the administrative databases for hospital admissions to compare outcomes in the periods before and after full implementation of the stroke system in 2005; we used the $\chi^{2}$ test for categorical variables and the $t$ test for continuous variables. We next used piecewise regression analyses to determine whether there was a change in rates of outcomes after 2005 beyond what would be expected from baseline temporal trends. We divided the 10 -year study period into monthly intervals and calculated rates for each outcome within each interval. In the piecewise regression model, we tested 3 parameters: $\beta_{1}$ (equal to time in monthly intervals) to measure the slope of the outcome before the intervention; $\beta_{2}$ (equal to the change in the outcome measure between the last time point before the intervention and the first time point after the intervention) to test whether the intervention had an immediate effect on rates of the outcome (change in level); and $\beta_{3}$ (equal to the difference in the slope of the period before the intervention and the slope of the period after the intervention) to determine whether the slope of the outcome changed after the intervention (change in slope). We plotted residuals over time and used the Durbin-Watson statistic to ensure that autocorrelation did not exist.

We standardized rates of hospital admissions and emergency department visits by age and sex, using the 2001 Ontario population as the standard population. We calculated mortality only for patients admitted to hospital, and rates were stratified by type of stroke and adjusted for age, sex and Charlson-Deyo comorbidity index score by use of logistic regression models and indirect standardization. We adjusted rates of discharge to long-term care facilities by age, sex, stroke type and Charlson-Deyo comorbidity index score. We calculated waiting times for carotid revascularization from the date of hospital admission for stroke to the date of surgery.

For rates of thrombolytic therapy, neuroimaging, carotid imaging, care in a stroke unit, dysphagia screening and use of antithrombotic therapy, we used the registry cohort and performed tests for trends over time using a survey logistic regression model. We did not perform piecewise regression analyses because of discontinuous data and insufficient data points. We performed secondary analyses with stratification by hospital type (stroke centre v. nonstroke centre).

\section{Results}

During the 10-year study period, there were 243287 emergency department visits and 163198 hospital admissions for acute stroke or transient ischemic attack. Overall, $49 \%$ of the study patients were men, and the median age was 75 years. Patient characteristics were similar in the periods before and after 2005 (Table 2).

The proportion of patients who received care at either a regional or district stroke centre increased from $40.0 \%$ before 2005 to $46.5 \%$ in the period after full implementation of the stroke care delivery system (Table $3 ; p<0.001$ ). Rates of discharge to long-term care facilities declined from $16.9 \%$ to $14.8 \%, 30$-day mortality after hemorrhagic stroke decreased from $38.3 \%$ to $34.4 \%$ and 30 -day mortality after ischemic 
stroke decreased from $16.3 \%$ to $15.7 \%$ after implementation of the Ontario Stroke System (Table 3; $p<0.01$ for all comparisons). The median length of stay decreased from 7 to 6 days $(p<0.001)$, and the median time from stroke presentation to carotid revascularization decreased from 50 to 22 days $(p<0.001)$ after 2005 (Table 3).
The piecewise regression analyses showed a gradual increase in rates of care at stroke centres between 2001 and 2005, followed by a significant upward shift in rates in 2005 ( $p<0.01$ for the change in level). This was not associated with an immediate shift in the risk of discharge to a long-term care facility after stroke or the risk of death, but rather it was associated with a

Table 2: Baseline characteristics of patients with stroke or transient ischemic attack, before (Jan. 1, 2001-Mar. 31, 2005) and after (Apr. 1, 2005-Dec. 31, 2010) full implementation of the Ontario Stroke System

\begin{tabular}{|c|c|c|c|}
\hline \multirow[b]{2}{*}{ Characteristic } & \multicolumn{2}{|c|}{$\%$ of patients* } & \multirow[b]{2}{*}{$\begin{array}{c}\text { Standardized } \\
\text { differencet }\end{array}$} \\
\hline & $\begin{array}{l}\text { Before implementation } \\
\qquad n=105354\end{array}$ & $\begin{array}{l}\text { After implementation } \\
\qquad n=137933\end{array}$ & \\
\hline Male & 49 & 49 & 0.01 \\
\hline Age, yr, median & 75 & 75 & 0.02 \\
\hline Transient ischemic attack & 34 & 35 & 0.02 \\
\hline \multicolumn{4}{|l|}{ Stroke type } \\
\hline Ischemic & 84 & 83 & 0.03 \\
\hline Intracerebral hemorrhage & 11 & 11 & 0.00 \\
\hline Subarachnoid hemorrhage & 4 & 5 & 0.02 \\
\hline \multicolumn{4}{|l|}{ Comorbid conditions } \\
\hline Hypertension & 40 & 46 & 0.12 \\
\hline Atrial fibrillation & 14 & 16 & 0.07 \\
\hline Diabetes mellitus & 17 & 24 & 0.16 \\
\hline Coronary artery disease & 13 & 11 & 0.09 \\
\hline \multicolumn{4}{|c|}{$\begin{array}{l}\text { *Unless stated otherwise. } \\
\text { tStandardized differences express the difference between the means of } 2 \text { populations as a proportion of the pooled standard } \\
\text { deviation and are less sensitive to large samples than traditional hypothesis testing with } p \text { values. Standardized differences } \\
\geq 0.10 \text { are considered significant. } \\
\neq \text { Calculated for the subgroup of patients admitted to hospital ( } n=71533 \text { for } 2001-2005 \text { and } n=91665 \text { for } 2005-2010 \text { ). }\end{array}$} \\
\hline
\end{tabular}

Table 3: Outcomes of patients with stroke or transient ischemic attack, before (Jan. 1, 2001-Mar. 31, 2005) and after (Apr. 1, 2005-Dec. 31, 2010) full implementation of the Ontario Stroke System

\begin{tabular}{|c|c|c|c|}
\hline \multirow[b]{2}{*}{ Outcome } & \multicolumn{2}{|c|}{$\%$ of patients* } & \multirow[b]{2}{*}{$p$ valuet } \\
\hline & $\begin{array}{l}\text { Before implementation } \\
\qquad n=105354\end{array}$ & $\begin{array}{l}\text { After implementation } \\
\qquad n=137933\end{array}$ & \\
\hline Care at a regional or district stroke centre & 40.0 & 46.5 & $<0.001$ \\
\hline $\begin{array}{l}\text { Discharge to a long-term or chronic care } \\
\text { facility } \ddagger \S\end{array}$ & 16.9 & 14.8 & $<0.001$ \\
\hline $\begin{array}{l}\text { Mortality at } 30 \mathrm{~d} \text { after hemorrhagic } \\
\text { stroke } \uparrow\end{array}$ & 38.3 & 34.4 & $<0.001$ \\
\hline Mortality at $30 \mathrm{~d}$ after ischemic stroke $\neq \rrbracket$ & 16.3 & 15.7 & 0.004 \\
\hline Length of stay, $d$, median $\ddagger \S$ & 7 & 6 & $<0.001$ \\
\hline $\begin{array}{l}\text { Waiting time for carotid } \\
\text { revascularization, } d \text {, median }\end{array}$ & 50 & 22 & $<0.001$ \\
\hline \multicolumn{4}{|c|}{$\begin{array}{l}\text { *Unless stated otherwise. } \\
\text { †Based on } \chi^{2} \text { test for categorical variables and } t \text { test for continuous variables. } \\
\text { fCalculated for the subgroup of patients admitted to hospital ( } n=71533 \text { for } 2001-2005 \text { and } n=91665 \text { for 2005-2010). } \\
\text { §Length of stay and discharge rates to long-term or chronic care facilities are adjusted for age, sex, stroke type and Charlson- } \\
\text { Deyo comorbidity index score. } \\
\text { १Mortality adjusted for age, sex and Charlson-Deyo comorbidity index score. }\end{array}$} \\
\hline
\end{tabular}


decrease in the slope of these outcomes after 2005 (Figure 1; $p<0.05$ for the change in slope for all outcomes).
Between 2002 and 2009, there were significant increases in rates of thrombolytic therapy (from $10 \%$ to $27 \%$ ), neuroimaging (from $77 \%$ to

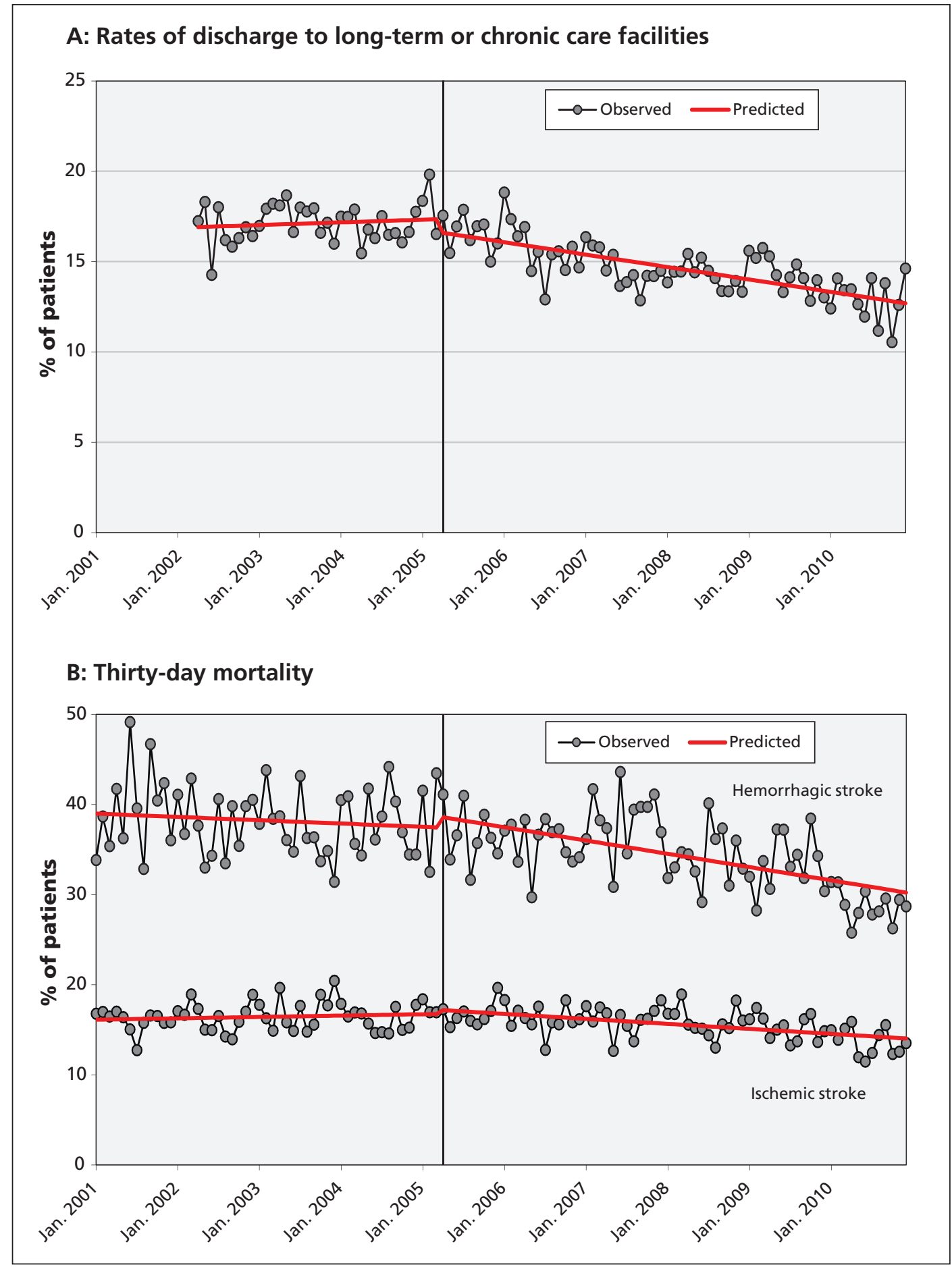

Figure 1: (A) Rates of discharge to long-term or chronic care facilities after admission to hospital for stroke or transient ischemic attack from Apr. 1, 2002, to Dec. 31, 2010, adjusted for age, sex, stroke type and Charlson-Deyo comorbidity index score $(p=0.1$ for a shift in rates after the intervention and $p<0.001$ for a decrease in the slope after the intervention, using piecewise regression analyses). (B) Thirty-day mortality for patients admitted to hospital with hemorrhagic or ischemic stroke from Jan. 1, 2001, to Dec. 31, 2010, adjusted for age, sex and Charlson-Deyo comorbidity index score. Hemorrhagic stroke: $p=0.4$ for a shift in rates after the intervention and $p=0.02$ for a decrease in the slope after the intervention, using piecewise regression analyses. Ischemic stroke: $p=0.4$ for a shift in rates after the intervention and $p<0.001$ for a decrease in the slope after the intervention, using piecewise regression analyses. 
Table 4: Care of patients with stroke or transient ischemic attack, from Apr. 1, 2002, to Mar. 31, 2009

\begin{tabular}{|c|c|c|c|c|}
\hline \multirow[b]{2}{*}{ Variable } & \multicolumn{3}{|c|}{$\%$ of patients* } & \multirow[b]{2}{*}{$p$ value $\dagger$} \\
\hline & $2002 / 03$ & $2004 / 05$ & 2008/09 & \\
\hline Sampleł & $n=3322$ & $n=4913$ & $n=3931$ & \\
\hline Applicable population $\ddagger$ & $n=25392$ & $n=23800$ & $n=22593$ & \\
\hline Neuroimaging§ performed & 77 & 82 & 93 & $<0.001$ \\
\hline Nondesignated centre & 73 & 77 & 89 & $<0.001$ \\
\hline District stroke centre & 78 & 84 & 96 & $<0.001$ \\
\hline Regional stroke centre & 88 & 96 & 98 & $<0.001$ \\
\hline $\begin{array}{l}\text { Thrombolytic therapy (if ischemic stroke and } \\
\text { presentation within } 2.5 \mathrm{~h} \text { of stroke onset) }\end{array}$ & 10 & 14 & 27 & $<0.001$ \\
\hline Nondesignated centre & 2 & 4 & 4 & 0.33 \\
\hline District stroke centre & 12 & 13 & 32 & $<0.001$ \\
\hline Regional stroke centre & 30 & 36 & 42 & $<0.05$ \\
\hline $\begin{array}{l}\text { Carotid imaging } \text { performed (if ischemic stroke } \\
\text { or TIA) }\end{array}$ & 44 & 55 & 68 & $<0.001$ \\
\hline Nondesignated centre & 43 & 49 & 62 & $<0.001$ \\
\hline District stroke centre & 49 & 61 & 67 & $<0.001$ \\
\hline Regional stroke centre & 51 & 70 & 81 & $<0.001$ \\
\hline $\begin{array}{l}\text { Antithrombotic therapy** (if ischemic stroke } \\
\text { or TIA) }\end{array}$ & 80 & 92 & 94 & $<0.001$ \\
\hline Nondesignated centre & 78 & 92 & 92 & $<0.001$ \\
\hline District stroke centre & 82 & 92 & 94 & $<0.001$ \\
\hline Regional stroke centre & 87 & 94 & 96 & $<0.001$ \\
\hline $\begin{array}{l}\text { Admission to a stroke unit (among those } \\
\text { admitted to hospital) }\end{array}$ & 3 & 11 & 24 & $<0.001$ \\
\hline Nondesignated centre & 3 & 2 & 4 & $<0.001$ \\
\hline District stroke centre & 2 & 7 & 33 & $<0.001$ \\
\hline Regional stroke centre & 4 & 41 & 52 & $<0.001$ \\
\hline $\begin{array}{l}\text { Dysphagia screening (among those admitted } \\
\text { to hospital) }\end{array}$ & 47 & 51 & 57 & $<0.001$ \\
\hline Nondesignated centre & 44 & 48 & 52 & $<0.001$ \\
\hline District stroke centre & 45 & 54 & 63 & $<0.001$ \\
\hline Regional stroke centre & 54 & 56 & 61 & $<0.001$ \\
\hline $\begin{array}{l}\text { All of neuroimaging, carotid imaging, care at a } \\
\text { stroke unit, dysphagia screening (among those } \\
\text { admitted to hospital) }\end{array}$ & & & & $<0.001$ \\
\hline Nondesignated centre & 2 & 1 & 4 & $<0.001$ \\
\hline District stroke centre & 1 & 6 & 26 & $<0.001$ \\
\hline Regional stroke centre & 2 & 32 & 47 & $<0.001$ \\
\hline Referral to a secondary prevention clinic & 14 & 29 & 57 & $<0.001$ \\
\hline Nondesignated centre & 7 & 21 & 49 & $<0.001$ \\
\hline District stroke centre & 17 & 27 & 64 & $<0.001$ \\
\hline Regional stroke centre & 40 & 67 & 77 & $<0.001$ \\
\hline \multicolumn{5}{|c|}{$\begin{array}{l}\text { Note: TIA = transient ischemic attack. } \\
\text { *Unless stated otherwise. } \\
\text { †Based on tests for trends over time using a survey logistic regression model. } \\
\text { †To account for oversampling at small-volume institutions, results are weighted based on hospital volume and the numb } \\
\text { charts sampled. By using weights in the analyses, an estimate that applies to the entire population was obtained. } \\
\text { SIncludes computed tomography and magnetic resonance imaging of the brain. } \\
\text { १Includes carotid Doppler ultrasonography, computed tomography angiography, magnetic resonance angiography and } \\
\text { catheter angiography. } \\
\text { **Includes acetylsalicylic acid, clopidogrel, dipyridamole and warfarin. }\end{array}$} \\
\hline
\end{tabular}


93\%), carotid imaging (from $44 \%$ to $68 \%$ ), care in a stroke unit (from 3\% to 24\%), dysphagia screening (from $47 \%$ to $57 \%$ ), antithrombotic therapy (from $80 \%$ to $94 \%$ ) and referrals to stroke prevention clinics (from 14\% to $57 \%$ ) (Table $4 ; p<0.001$ for all comparisons). Although improvements in care across the study period were seen at all hospital types, increases in care in a stroke unit and rates of thrombolytic therapy were greater at district and regional stroke centres, with little or no change at nondesignated centres (Table 4).

\section{Interpretation}

We found that implementation of a provincial system of stroke care delivery was associated with increased rates of care at specialized stroke centres, improved processes of acute stroke care delivery and decreased rates of admission to a long-term care facility and death after stroke beyond what would be expected based on underlying temporal trends.

Stroke systems of care are designed to coordinate and optimize delivery of care across the continuum of stroke, from primary prevention to rehabilitation and reintegration. ${ }^{11,1,2,20,26}$ The American Stroke Association has provided detailed recommendations for the establishment of such systems, with key elements including collaboration among providers, the use of telemedicine to facilitate patient care in remote institutions and the identification of performance measures to evaluate the effectiveness of the system. ${ }^{11,27}$ In the area of acute care, the system of stroke care delivery should include the designation of comprehensive stroke centres and the development of regional strategies to ensure that all eligible patients receive interventions such as thrombolytic therapy and care in a stroke unit. The Ontario Stroke System includes all of these components.

Although a randomized controlled trial would be the most methodologically rigorous means of evaluating the effectiveness of a stroke system of care, this was not feasible in Ontario because of the complexity of the intervention and the desire to rapidly implement the system of care across the entire province. Instead, we used piecewise regression analyses to study the effect of the implementation of the system on outcomes among patients with stroke. Such analyses are a more robust experimental design than simple before-and-after comparisons because they allow the effect of the intervention to be distinguished from underlying temporal trends in outcomes and permit the assessment of both immediate and delayed changes in outcomes. ${ }^{28,29}$ Although a true causal relation between implementation of the Ontario Stroke System and improved patient outcomes cannot be established definitively on the basis of our study, the likelihood of a causal association is strengthened by the lack of major temporal confounders and by the concomitant improvements observed in processes of care, including those (i.e., care at a stroke centre, care in a stroke unit, thrombolytic therapy, medications for secondary stroke prevention) that have been previously shown to be associated with reduced death or disability from stroke. ${ }^{30-34}$

Although we observed an increase in the proportion of patients seen at designated stroke centres over the study period, the absolute magnitude of the increase was modest, with more than half of the population receiving care at nondesignated centres even 5 years following the full implementation of the stroke system. This is presumably a consequence of the system being designed primarily to facilitate the transfer or bypass of only those patients most likely to be candidates for thrombolytic therapy or neurosurgical interventions. Therefore, although the implementation of the system was associated with only about 1600 additional people receiving care at a stroke centre each year, this was accompanied by marked increases in rates of thrombolytic therapy and care in a stroke unit. The observed decreases in stroke-related mortality and admissions to long-term care facilities were relatively small. However, when applied to the population with stroke in Ontario, these decreases would be expected to result in about 200 fewer stroke-related deaths and 300 fewer patients requiring long-term or chronic care each year.

Despite the province-wide scope of the Ontario Stroke System, previous audits have shown persistent regional variations in care, and it is likely that access to care remains particularly challenging for patients in remote or rural areas. ${ }^{23}$ Although an ideal system might see all patients receiving care at specialized stroke centres, this may be difficult to achieve in large, geographically diverse jurisdictions such as Ontario. Such a system could also have unintended negative consequences, such as increased patient volumes at stroke centres and the need for transfer and assessment of patients who are later determined to have not had a stroke. Increased use of telemedicine may serve as a feasible alternative to ensure delivery of highquality stroke care across an entire region, including remote areas. Between 2002 and 2012, the Ontario Telestroke Program provided neurologist consultation to about 3000 patients with stroke, $30 \%$ of whom received thrombolytic therapy. ${ }^{22}$ 


\section{Limitations}

Some limitations of our study merit emphasis. Although we studied the effect of the full implementation of the Ontario Stroke System in 2005, a phased introduction of the system occurred between 2000 and 2005, and thus our analyses almost certainly underestimate the overall effect of the stroke system on care and outcomes. Our study focused on hospital-based processes of care and outcomes, and we do not have information on longer-term outcomes such as functional status, quality of life or after-stroke care.

Although the piecewise regression analyses helped to distinguish the effect of the system from underlying temporal trends in care, they did not account for the potential effects of concurrent interventions. For example, the publication in 2004 of data suggesting that carotid endarterectomy is most effective if performed within 2 weeks of acute stroke $^{35}$ likely contributed to the decline in waiting times for carotid revascularization before and after 2005. However, it is unlikely that all of the observed improvements in other outcomes could be fully explained by alternative interventions.

In our outcome analyses, we adjusted for key prognostic variables, including age, type of stroke and comorbid illness, but we were unable to adjust for stroke severity because this variable was not captured in our administrative data sources.

We did not evaluate the individual components of the Ontario Stroke System, and this study does not provide information on the relative effectiveness of the various interventions within the system. However, previous observational studies suggest that the establishment of stroke centres and the use of prehospital protocols may lead to improved processes of stroke care delivery. ${ }^{36,37}$

We did not perform a cost-effectiveness analysis; however, many of the individual components of the stroke system have been shown to be cost-effective. ${ }^{38-42}$

Finally, stroke care in Ontario is delivered within the context of Canada's universal health care system, and our results and outcomes may not be easily replicated in countries without a single-payer system.

\section{Conclusion}

This study assessed the effect of the implementation of a system of stroke care delivery on important outcomes, including death and admission to a long-term or chronic care facility after stroke. Our findings provide strong support for the ongoing development and implementation of regional systems of organized stroke care delivery. Future research should focus on identifying the specific components of such systems that are most likely to account for improvements in outcomes.

\section{References}

1. Donnan GA, Fisher M, Macleod M, et al. Stroke. Lancet 2008; 371:1612-23.

2. Rosamond W, Flegal K, Friday G, et al. Heart disease and stroke statistics 2007 update: a report from the American Stroke Association Statistics Committee and Stroke Statistics Subcommittee. Circulation 2007;115:e69-171.

3. Adams HP, del Zoppo G, Alberts MJ, et al. Guidelines for the early management of adults with ischemic stroke. A guideline from the American Heart Association/American Stroke Association Stroke Council, Clinical Cardiology Council, Cardiovascular Radiology and Intervention Council, and the Atherosclerotic Peripheral Vascular Disease and Quality of Care Outcomes in Research Interdisciplinary Working Groups. Stroke 2007;38: 1655-711.

4. National Stroke Foundation. Clinical guidelines for stroke management 2010. Melbourne (Australia): The Foundation; 2010. Available: www.nhmrc.gov.au/_files_nhmrc/publications /attachments/cp126.pdf (accessed 2013 May 7).

5. European Stroke Organization (ESO) Executive Committee, ESO Writing Committee. Guidelines for the management of ischaemic stroke and transient ischaemic attack 2008. Cerebrovasc Dis 2008;25:457-507.

6. National Collaborating Centre for Chronic Conditions. Stroke: diagnosis and initial management of acute stroke and transient ischaemic attack (TIA). London (UK): National Institute for Health and Clinical Excellence; 2008. Available: www.nice.org .uk/nicemedia/pdf/CG68NICEGuideline.pdf (accessed 2012 Jan. 23).

7. Goldstein LB. Statewide hospital-based stroke services in North Carolina: changes over 10 years. Stroke 2010;41:778-83.

8. Leys D, Ringelstein EB, Kaste M, et al.; Executive Committee of the European Stroke Initiative. Facilities available in European hospitals treating stroke patients. Stroke 2007;38:2985-91.

9. Barber PA, Gommans J, Fink J, et al. Acute stroke services in New Zealand: changes between 2001 and 2007. N Z Med J 2008; 121:46-51.

10. Dennis M, Dodds H, Flaig R, et al. Scottish stroke care audit 2011 national report: stroke services in Scottish hospitals. Edinburgh (UK): NHS National Services Scotland; 2011. Available: www.strokeaudit.scot.nhs.uk/Downloads/2011_National_Report .html (accessed 2012 Jan. 23)

11. Schwamm LH, Pancioli A, Acker JE, et al. Recommendations for the establishment of stroke systems of care: recommendations from the American Stroke Association's Task Force on the Development of Stroke Systems. Stroke 2005;36:690-703.

12. Norrving B, Adams RJ. Organized stroke care. Stroke 2006;37: 326-8.

13. Towards an integrated stroke strategy for Ontario: report of the Joint Stroke Strategy Working Group. Toronto (ON): Ontario Ministry of Health and Long-Term Care; 2000. Available: www.health.gov.on.ca/en/common/ministry/publications/reports /stroke/strokereport.pdf (accessed 2013 May 7)

14. Population and dwelling counts for Canada, provinces and territories, 2011 and 2006 censuses. Ottawa (ON): Statistics Canada; 2013. Available: www12.statcan.gc.ca/census-recensement/2011/dp -pd/hlt-fst/pd-pl/Table-Tableau.cfm?T=101\&S=50\&O=A (accessed 2013 May 7).

15. Kapral MK, Hall R, Stamplecoski M, et al. Registry of the Canadian Stroke Network - report on the 2008/09 Ontario Stroke Audit. Toronto (ON): Institute for Clinical Evaluative Sciences; 2011. Available: www.ices.on.ca/file/RCSN_Stroke _Audit_2011.pdf (accessed 2013 Jan. 21).

16. Juurlink DN, Preyra C, Croxford R, et al. Canadian Institute for Health Information Discharge Abstract Database: a validation study. Toronto (ON): Institute for Clinical Evaluative Sciences; 2006.

17. CIHI data quality study of the 2007-2008 Discharge Abstract Database. Ottawa (ON): Canadian Institute for Health Information; 2010.

18. Kokotailo RA, Hill MD. Coding of stroke and stroke risk factors using International Classification of Diseases, revisions 9 and 10. Stroke 2005;36:1776-81.

19. Canadian Stroke Strategy core performance indicator update 2010. Ottawa (ON): Canadian Stroke Network; 2010. Available: http://strokebestpractices.ca/wp-content/uploads/2010/12/Stroke _Core_ENG.pdf (accessed 2013 Jan. 21).

20. Lindsay P, Bayley M, Hellings C, et al. Canadian best practice recommendations for stroke care: summary (updated 2010). CMAJ 2008;179(Suppl):S1-25.

21. Deyo RA, Cherkin DC, Ciol MA. Adapting a clinical comorbidity index for use with ICD-9-CM administrative databases J Clin Epidemiol 1992;45:613-9. 
22. Waite K, Silver F, Jaigobin C, et al. Telestroke: a multi-site, emergency-based telemedicine service in Ontario. J Telemed Telecare 2006;12:141-5.

23. Hall R, Khan F, O'Callaghan C, et al. Ontario Stroke System Evaluation Report 2011: improving system efficiency by implementing stroke best practices. Toronto $(\mathrm{ON})$ : Institute for Clinical Evaluative Sciences; 2011. Available: www.ontariostroke network.ca (accessed 2013 Jan. 21).

24. Alberts MJ, Latchaw RE, Selman WR, et al. Recommendations for comprehensive stroke centers. A consensus statement from the Brain Attack Coalition. Stroke 2005;36:1597-616.

25. Austin PC. Using the standardized difference to compare the prevalence of a binary variable between two groups in observational research. Comm Statist Simulation Comput 2009;38:1228-34.

26. Suarez JI, Kent TA. The time is right to improve organization of stroke care. Neurology 2008:70:1232-3.

27. Schwamm LH, Audebert HJ, Amarenco P, et al. Recommendations for the implementation of telemedicine within stroke systems of care: a policy statement from the American Heart Association. Stroke 2009;40:2635-60.

28. Wagner AK, Soumerai SB, Zhang F, et al. Segmented regression analysis of interrupted time series studies in medication use research. J Clin Pharm Ther 2002;27:299-309.

29. McGee VE. Piecewise regression. J Am Stat Assoc 1970;65 1109-24.

30. Xian Y, Holloway RG, Chan PS, et al. Association between stroke center hospitalization for acute ischemic stroke and mortality. JAMA 2011;305:373-80.

31. Lichtman JH, Jones SB, Wang Y, et al. Outcomes after ischemic stroke for hospitals with and without Joint Commission-certified primary stroke centers. Neurology 2011;76:1976-82.

32. Wardlaw JM, Murray V, Berge E, et al. Thrombolysis for acute ischaemic stroke. Cochrane Database Syst Rev 2009;(4): CD000213.

33. Stroke Unit Trialists' Collaboration. Organised inpatient (stroke unit) care for stroke. Cochrane Database Syst Rev 2006;(4): CD000197.

34. Furie KL, Kasner SE, Adams RJ, et al. Guidelines for the prevention of stroke in patients with stroke or transient ischemic attack: a guideline for healthcare professionals from the American Heart Association/American Stroke Association. Stroke 2011;42:227-76.

35. Rothwell PM, Eliasziw M, Gutnikov SA, et al. Endarterectomy for symptomatic carotid stenosis in relation to clinical subgroups and timing of surgery. Lancet 2004;363:915-24

36. Douglas VC, Tong DC, Gillum LA, et al. Do the Brain Attack Coalition's criteria for stroke centers improve care for ischemic stroke? Neurology 2005;64:422-7.

37. Gladstone DJ, Rodan LH, Sahlas DJ, et al. A citywide prehospital protocol increases access to stroke thrombolysis in Toronto. Stroke 2009;40:3841-4.

38. Ehlers L, Andersen G, Clausen LB, et al. Cost-effectiveness of intravenous thrombolysis with alteplase within a 3-hour window after acute ischemic stroke. Stroke 2007;38:85-9.

39. Moodie M, Cadilhac D, Pearce D, et al. Economic evaluation of Australian stroke services: a prospective, multicenter study com- paring dedicated stroke units with other care modalities. Stroke 2006;37:2790-5.

40. van Exel NJ, Koopmanschap MA, Scholte op Reimer W, et al. Cost-effectiveness of integrated stroke services. Q J Med 2005;98: 415-25.

41. Krueger H, Lindsay MP, Cote R, et al. Cost-avoidance associated with optimal stroke care in Canada. Stroke 2012;43:2198-206.

42. Launois R, Giroud M, Megnigbeto AC, et al. Estimating the cost-effectiveness of stroke units in France compared with conventional care. Stroke 2004;35:770-5.

Affiliations: From the Department of Medicine (Kapral, Silver, Tu), University of Toronto; the Institute of Health Policy, Management and Evaluation (Kapral, Hall, Tu), University of Toronto; the Institute for Clinical Evaluative Sciences (Kapral, Fang, Hall, Stamplecoski, Tu); the Division of General Internal Medicine and Toronto General Research Institute (Kapral), University Health Network; the Division of Neurology (Silver), University Health Network; the Ontario Stroke Network (O'Callaghan); and the Schulich Heart Centre and Clinical Epidemiology Unit (Tu), Sunnybrook Health Sciences Centre, Toronto, Ont.

Contributors: Moira Kapral was responsible for the conception of the study, and Jiming Fang performed the statistical analyses. All of the authors contributed to the study design, analysis plan and interpretation of results. Moira Kapral drafted the manuscript, which all of the authors revised. All of the authors gave final approval of the version submitted for publication.

Funding: The Ontario Stroke Registry is funded by the Canadian Stroke Network and the Ontario Ministry of Health and Long-Term Care. The Institute for Clinical Evaluative Sciences is supported by an operating grant from the Ontario Ministry of Health and Long-Term Care. The results and conclusions are those of the authors and should not be attributed to any supporting or sponsoring agencies. The funding agencies had no involvement in the design and conduct of the study; collection, management, analysis, and interpretation of the data; or preparation, review or approval of the manuscript.

Moira Kapral holds a Career Investigator Award from the Heart and Stroke Foundation of Canada. Frank Silver is supported by the Canadian Stroke Network. Jack Tu holds a Canada Research Chair in Health Services Research and a Career Investigator Award from the Heart and Stroke Foundation of Ontario.

Acknowledgements: The authors thank Peter Austin, David Juurlink and Muhammad Mamdani for helpful comments on earlier versions of this manuscript 